\title{
Quantification of right to left shunt at rest and during exercise in patients with pulmonary arteriovenous malformations
}

\author{
Moira K B Whyte, A M Peters, J M B Hughes, B L Henderson, G J Bellingan, \\ J E Jackson, E R Chilvers
}

\begin{abstract}
Background Current treatment of patients with pulmonary arteriovenous malformations requires serial embolisations by means of steel coils or balloons. Measurement of right to left shunt is the most specific index of response to treatment. A new method of measuring shunt has been developed that is less invasive than traditional methods.

Methods Right to left pulmonary shunt (expressed as percentage of cardiac output) was measured at rest in 19 patients with pulmonary arteriovenous malformations and six normal subjects by using intravenously injected albumin microspheres labelled with technetium-99m. The technique was compared with a simultaneous shunt measurement in subjects breathing $100 \%$ oxygen while they rested. The microsphere technique was adapted to measure the right to left shunt during exercise in 12 patients and five normal subjects with a new method of quantification.
\end{abstract}

Results The mean (SD) shunt at rest as measured by the microsphere method was $23.2 \%(15.6 \%)$ in the patients and $2 \cdot 7 \%(1 \cdot 2 \%)$ in the normal subjects. When these values were compared with those of the $100 \%$ oxygen method the difference in mean values was $1 \%$ and the limits of agreement between the two methods $-32 \%$ to $+45 \%$. The microsphere method is less invasive (arterial blood gas sampling is not required), quicker, and more comfortable for patients than the $100 \%$ oxygen method. In five of the normal subjects the mean (SD) ${ }^{99 m}$ Tc microsphere shunt increased from $2.9 \%(1 \cdot 3 \%)$ at rest to $5 \cdot 1 \%(2.9 \%)$ during exercise. In the 12 patients studied during exercise the shunt increased from $33 \cdot 7 \%(12 \cdot 7 \%)$ at rest to $41 \cdot 7 \%(13 \cdot 3 \%)$ during exercise in eight but decreased from $22.6 \%(2 \cdot 4 \%)$ at rest to $17 \cdot 6 \%(2 \cdot 2 \%)$ during exercise in four. Arterial desaturation during exercise correlated with change in the size of the right to left shunt during exercise $(\mathbf{r}=+\mathbf{0 . 8 0})$.

Conclusions The microsphere method allows measurement of right to left shunt at rest and during exercise. Serial measurements at rest provide a simple, safe assessment of the physiological response to embolisation in patients with pulmonary arteriovenous malformations.

(Thorax 1992;47:790-796)

Major advances have been made in the treatment of pulmonary arteriovenous malformations in the last decade, based on percutaneous transcatheter embolisation with steel coils ${ }^{1}$ or balloons, ${ }^{23}$ with a greatly reduced need for surgical resection. This, combined with increasing recognition of the high incidence of neurological sequelae from paradoxical embolisation, ${ }^{2-4}$ has meant that early intervention is recommended for most patients. ${ }^{56}$

The classical triad of physical signs of pulmonary arteriovenous malformations consists of cyanosis, clubbing, and an overlying bruit and one or more of these is present in about three quarters of patients with pulmonary arteriovenous malformation. ${ }^{7}$ Arterial oxygen tension was reduced in more than $80 \%$ of cases studied by Dines et al. ${ }^{4}$ All 15 patients in our previous series had a resting arterial oxygen saturation $\left(\mathrm{SaO}_{2}\right)$ below $95 \%$ when it was measured supine, further desaturation occurring in the standing position and with exercise. ${ }^{8}$ The diagnosis of pulmonary arteriovenous malformations and assessment of shunt size are important both in the initial evaluation of patients and in monitoring the effects of treatment. Extra-alveolar shunt is usually measured by the classical $100 \%$ oxygen breathing method. ${ }^{9}$ We have recently described a method using technetium-99m albumin microspheres, 7-25 $\mu \mathrm{m}$ in diameter, to quantify right to left shunt at rest. ${ }^{10}$ As particles greater than $8 \mu \mathrm{m}$ in diameter are normally trapped in the pulmonary capillary bed, passage of larger particles into the systemic circulation represents a right to left shunt.

Chilvers $e t a l^{8}$ commented on the increase in arterial oxygen desaturation that occurs with exercise in patients with pulmonary arteriovenous malformations, despite good exercise capacity in many cases. The mechanism of the progressive hypoxaemia during exercise is not understood. Possible explanations include (1) an increase in the right to left shunt; (2) increased tissue oxygen extraction, leading to the addition of very desaturated mixed venous blood to the systemic arterial blood via the arteriovenous malformation; (3) increasing ventilation-perfusion $(\dot{\mathbf{V}} / \mathbf{Q})$ mismatch.

This paper reports measurement of shunt by 
the microsphere method and by the $100 \%$ oxygen method in 19 patients with pulmonary arteriovenous malformations and in six normal subjects at rest. In addition, we have adapted the ${ }^{99 \mathrm{~m}} \mathrm{Tc}$ microsphere method to measure shunt size during exercise. The results in 12 patients and five normal subjects are presented below.

\section{Methods}

MEASUREMENT OF RIGHT TO LEFT SHUNT AT REST We studied 19 patients (10 female; age 13-66, mean 44 years) with pulmonary arteriovenous malformations on pulmonary angiography. Thirty six measurements of right to left shunt were obtained, serial measurements being performed in some patients. Clinical details are given in table 1. No patient had hepatic or renal impairment according to routine biochemical investigations. Fourteen of the 19 patients had hereditary haemorrhagic telangiectasia. Nine patients had had a previous thoracotomy, with ligation of pulmonary arteriovenous malformations in three and partial or total lobectomy in six. Six normal volunteers were also studied (one female; age 28-52, mean 36 years). Ethical permission was obtained from the local ethics committee and the patients and normal volunteers gave informed consent.

Measurement of right to left shunt at rest was performed by two independent methods: the $100 \%$ oxygen method and the technetium $-99 \mathrm{~m}$ labelled albumin microsphere method.

\section{$100 \%$ oxygen method}

Shunt was measured in the supine posture, with the patient breathing $100 \%$ oxygen from a Douglas bag, via a mouthpiece, two way valve, and noseclip to ensure delivery of $100 \%$ oxygen. The patient was asked to make every tenth breath as deep as possible to accelerate nitrogen washout. Arterial oxygen saturation $\left(\mathrm{SaO}_{2}\right)$ was measured by pulse oximeter (Ohmeda Biox 3700) during the procedure. When the subject had breathed $100 \%$ oxygen for 20 minutes an arterial blood sample was taken, cooled on ice, and analysed rapidly for arterial oxygen tension $\left(\mathrm{PaO}_{2}\right)$. As the right to left shunt may be increased at high lung volumes, ${ }^{11}$ blood was drawn during and for five seconds after the patient had paused at functional residual capacity. The right to left shunt was calculated from the $\mathrm{PaO}_{2}$ and $\mathrm{SaO}_{2}$ values obtained while the subject breathed $100 \%$ oxygen and the haemoglobin concentration (in $\mathrm{g} / \mathrm{dl}$ ) by using the classical equation. ${ }^{89}$

Technetium-99m albumin microsphere method Microspheres were injected immediately after arterial blood gas sampling. While the patient remained supine, breathing $100 \%$ oxygen, 110 $\mathrm{MBq}$ of technetium-99m microspheres 7-25 $\mu \mathrm{m}, 0.4 \times 10^{6}$ particles $/ \mathrm{mg}$; TCK-5-S, CIS, Sorin Biomedica, Saluggia, Italy) were injected via an antecubital vein, again with the patient at functional residual capacity. After five minutes images were obtained of the upper abdomen (posterior and lateral views) and lungs (posterior views). An International General Electric 400A gamma camera was used, fitted with a parallel hole, general purpose, low energy collimator and on line to a computer (Medical Data Systems $\mathrm{A}^{2}$ ). Thus total counts were obtained from regions of interest over the right kidney and the right and left lungs. The depth of the right kidney was determined from the number of pixels between the skin marker and the centre of the kidney on the right lateral image. Total lung radioactivity was taken to be the sum of the counts, in the posterior view, in the regions of interest over the right and left lungs. The total injected microsphere radioac-

Table 1 Clinical details, presence or absence of hereditary haemorrhagic telangiectasia (HHT) and arterial oxygen saturation $\left(\mathrm{SaO}_{2}\right)$ in erect and supine postures in all 26 patients with pulmonary arteriovenous malformations

\begin{tabular}{|c|c|c|c|c|c|c|c|}
\hline \multirow{2}{*}{$\begin{array}{l}\text { Patient } \\
\text { No }\end{array}$} & \multirow[b]{2}{*}{ Age $(y)$} & \multirow[b]{2}{*}{ Sex } & \multirow[b]{2}{*}{$H H T$} & \multirow[b]{2}{*}{ Presentation } & \multirow{2}{*}{$\begin{array}{l}\text { Haemoglobin } \\
(\mathrm{g} / \mathrm{dl})\end{array}$} & \multicolumn{2}{|l|}{$\mathrm{SaO}_{2}$} \\
\hline & & & & & & Erect & Supine \\
\hline $1 *$ & 27 & $\mathbf{F}$ & + & Dyspnoea, cyanosis & $18 \cdot 4$ & 80 & 84 \\
\hline $2 \star$ & 13 & $F$ & + & Epistaxis, cyanosis & $18 \cdot 1$ & 65 & 76 \\
\hline $3 \star$ & 40 & $\mathbf{M}$ & + & Dyspnoea, epistaxis & $17 \cdot 6$ & 74 & 85 \\
\hline $4^{\star}$ & 26 & $\mathbf{M}$ & - & Abnormal chest radiograph & $19 \cdot 5$ & 82 & 90 \\
\hline $5^{\star}$ & 25 & $\mathbf{M}$ & + & Abnormal chest radiograph & $19 \cdot 1$ & 88 & 91 \\
\hline 6 & 47 & $\mathbf{F}$ & + & Epistaxis & $12 \cdot 3$ & 84 & 89 \\
\hline 7 & 48 & $\mathbf{F}$ & + & Dyspnoea, epistaxis & $13 \cdot 4$ & 90 & 94 \\
\hline 8 & 63 & $\mathbf{F}$ & + & Transient ischaemic attacks & $18 \cdot 1$ & 79 & 87 \\
\hline 9 & 42 & $\mathbf{M}$ & - & Dyspnoea, polycythaemia & $16 \cdot 8$ & 82 & 88 \\
\hline 10 & 34 & $\mathbf{M}$ & + & Epistaxis, migraine & $15 \cdot 5$ & 93 & 95 \\
\hline 11 & 56 & $\mathbf{M}$ & + & Epistaxis & $15 \cdot 9$ & 88 & 93 \\
\hline 12 & 57 & $\mathbf{F}$ & + & Epistaxis & $8 \cdot 1$ & 91 & 91 \\
\hline 13 & 42 & $\mathbf{F}$ & - & Abnormal chest radiograph & $13 \cdot 8$ & 95 & 96 \\
\hline 14 & 51 & $\mathbf{M}$ & - & Transient ischaemic attacks & $15 \cdot 7$ & 87 & 92 \\
\hline 15 & 36 & $\mathbf{M}$ & - & Transient ischaemic attacks & $17 \cdot 3$ & 96 & 98 \\
\hline 16 & 29 & $\mathbf{F}$ & + & Epilepsy, epistaxis & $13 \cdot 4$ & 70 & 79 \\
\hline 17 & 57 & $\mathbf{F}$ & + & Epistaxis & $11 \cdot 8$ & 96 & 96 \\
\hline 18 & 35 & $\mathbf{M}$ & - & Cyanosis & $16 \cdot 6$ & 94 & 94 \\
\hline 19 & 16 & $\mathbf{F}$ & + & Epistaxis & $15 \cdot 4$ & 97 & 97 \\
\hline $20^{\star}$ & 59 & $\mathbf{F}$ & + & Transient ischaemic attacks & $13 \cdot 3$ & 74 & 88 \\
\hline 21 * & 66 & $\mathbf{M}$ & - & Dyspnoea, cyanosis & $14 \cdot 0$ & 65 & 87 \\
\hline $22^{\star}$ & 52 & $\mathbf{F}$ & + & Cerebral abscess & $16 \cdot 0$ & 80 & 91 \\
\hline $23^{\star}$ & 40 & $\mathbf{F}$ & - & Transient ischaemic attacks & 13.7 & 86 & 90 \\
\hline $24^{\star}$ & 20 & $\mathbf{F}$ & - & Dyspnoea & $17 \cdot 5$ & 73 & 85 \\
\hline $25^{\star}$ & 31 & $\mathbf{F}$ & + & Cyanosis & $16 \cdot 1$ & 93 & 95 \\
\hline $26^{\star}$ & 51 & $\mathbf{F}$ & + & Abnormal chest radiograph & 16.9 & 93 & 96 \\
\hline
\end{tabular}

${ }^{\star}$ Had right to left shunt measurements at rest and on exercise. 
Figure 1 -Posterior image taken two minutes after injection of ${ }^{99 m} \mathrm{Tc}$ microspheres at rest, showing uptake in both lungs ( $R L$ and $L L$ ) and systemic uptake in the right kidney $(R K)$, left kidney ( $L K)$, and spleen (S). B-Posterior image from the same patient, after injection of ${ }^{99 m} \mathrm{TC}$ microspheres during exercise. Note the decrease in uptake by the kidneys compared with the uptake during rest and the increased perfusion of the lung apices.

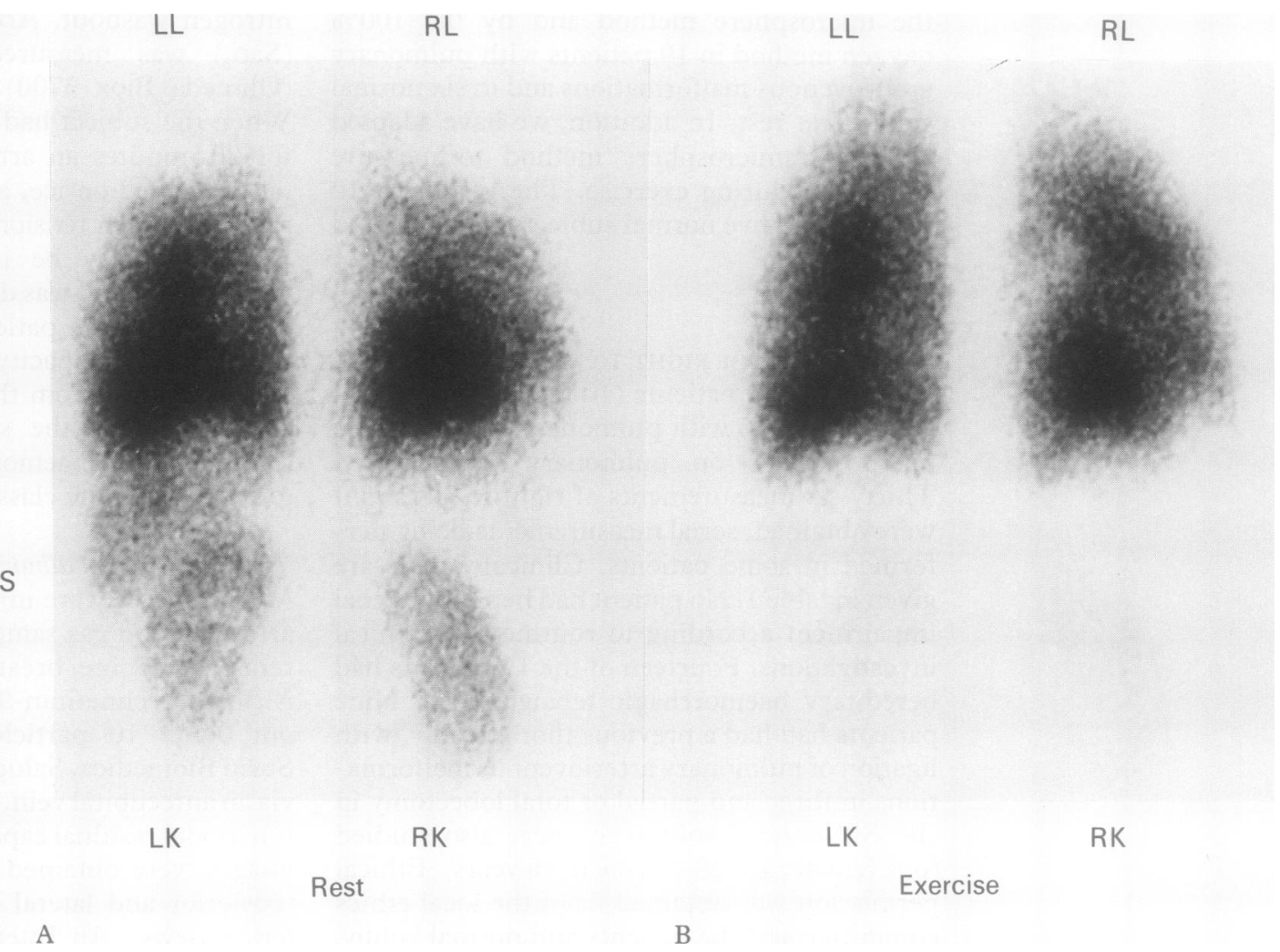

tivity was measured by counting the syringe that contained the dose, before and after injection, on a $3 \mathrm{~cm}$ thick perspex block resting on the face of the collimated gamma camera. According to the time at which each image was obtained, corrections were made for the decay of ${ }^{99 \mathrm{~m}} \mathrm{Tc}$ (half life 360 minutes).

Measurement of the shunt was performed in two ways:

Kidney:dose method The right kidney was used in preference to the left because splenic uptake of microspheres may be considerable (fig 1A) whereas the liver, receiving more than three quarters of its blood supply from the portal vein and little from the hepatic artery, shows very little uptake. Counts in the region of interest of the right kidney were corrected for attenuation, an attenuation coefficient obtained from previous phantom studies being used and expressed as a percentage of the injected dose. The right kidney was assumed to receive $10 \%$ of the systemic cardiac output at rest (on the basis of previous radionuclide studies of renal blood flow)..$^{1213}$ Thus

shunt fraction $=\frac{\text { right kidney counts } \times 10 \times \text { attenuation constant }}{\text { microsphere counts injected }}$

Kidney:lung method The following equation was used:

shunt fraction $=\frac{\text { right kidney counts } \times 10}{(\text { right kidney counts } \times 10)+\text { total lung counts }}$

No corrections were made for attentuation when this method was applied.

MEASUREMENT OF RIGHT TO LEFT SHUNT DURING EXERCISE

Right to left shunt was measured during exercise in 12 patients (eight female; age 13-66, mean 37 years) with pulmonary arteriovenous malformations (table 1, Patients 1-5 and 20-26) on 19 occasions and in five normal subjects (one female; age 28-52, mean 34 years).

\section{METHOD}

Incremental exercise testing was performed in the seated, erect posture, with a cycle ergometer. Patients rested for one hour and then exercised at $50 \%$ of their previously determined maximum workload for five minutes. Heart rate (from an electrocardiograph monitor) and $\mathrm{SaO}_{2}$ were recorded at the end of each minute. At the end of five minutes, with the patient continuing to cycle, $110 \mathrm{MBq}$ of ${ }^{99 \mathrm{~m}}$ Tc microspheres were injected via a $19 \mathrm{G}$ Butterfly cannula, previously inserted into a forearm vein. Imaging of the upper abdomen and both lungs was performed as soon as possible, as described above. On the next day a background count was obtained from the gamma camera, followed by measurement of resting shunt, as above, with the patient seated.

The equations used to calculate shunt flow at rest cannot be used for shunt flow during exercise. The redistribution of pulmonary blood flow, mainly to the lung apices, during exercise means that total lung counts must be obtained for both lungs. There is also marked redistribution of systemic blood flow on exercise, so the assumption that each kidney receives $10 \%$ of the cardiac output is no longer valid (fig 1B).

The change in shunt flow can be related to the change in lung activity with exercise, however, as lung counts reflect the proportion of cardiac obtained at rest and during exercise, per $\mathrm{MBq}$ of injected dose, and the ratio lung counts (exercise): lung counts (rest) is expressed as a fraction, $f$. output that is not shunted. Lung counts are 
Thus:

$$
\frac{1-\operatorname{shunt}(\text { exercise })}{1-\operatorname{shunt}(\text { rest })}=\mathrm{f} .
$$

Therefore

$\operatorname{shunt}($ exercise $)=1-\mathrm{f} .[1-\operatorname{shunt}($ rest $)]$

All shunt values are expressed as fractions. If shunt(rest) is measured as before and the $f$ value measured as the ratio in lung counts between exercise and rest, shunt(exercise) can be derived. An $\mathrm{f}$ value less than 1 will reflect reduced lung counts during exercise and thus an increase in shunt flow, whereas an $f$ value greater than 1 will indicate a reduction in right to left shunt with exercise.

\section{STATISTICAL METHODS}

Shunt measurements by the microsphere and $100 \%$ oxygen methods were compared by the method for assessing agreement between two measurements as described by Bland and Altman. ${ }^{14}$ Data were logarithmically transformed because the differences between the two methods increased as the shunt size increased.

Shunt sizes, $f$ values, and arterial oxygen saturation were compared at rest and during exercise within subjects by paired $t$ tests and between groups during exercise by unpaired $t$ tests.

\section{Results}

\section{SHUNT MEASUREMENT AT REST}

The patients had a mean (SD) shunt of $22 \cdot 2$ $(13.4 \%)$ at rest according to the $100 \%$ oxygen method, $23.2 \%(15 \cdot 6 \%)$ according to the kidney:dose microsphere method, and $23.8 \%$ $(17 \cdot 1 \%)$ according to the kidney:lung microsphere method. The right to left shunts obtained by the $100 \%$ oxygen method are compared with those obtained by the kidney:dose microsphere method and kidney:lung microsphere method in the 19 patients studied at rest in fig 2 . The difference between mean values for the kidney:dose and $100 \%$ oxygen methods was $1.0 \%$, and the $95 \%$ limits of agreement between the two methods were $-32 \%$ to $+45 \%$ (fig 3A). The difference between mean values obtained by the kidney:lung and the $100 \%$ oxygen methods was $1.0 \%$, and the $95 \%$ limits of agreement between the two methods were $-37 \%$ to $+57 \%$ (fig 3B)

In the six normal subjects the mean (SD) shunt (kidney:lung) was $2 \cdot 7 \%(1 \cdot 2 \%)$. The upper $95 \%$ confidence limit of $5 \cdot 1 \%$ may be used to define the upper limit of normal results obtained by the microsphere method.

\section{SHUNT MEASUREMENT DURING EXERCISE}

In five normal subjects (table 2 ) the mean (SD) value of $\mathrm{f}$ was $0.98(0.04)$, with mean shunt values of $2.9 \%(1.3 \%)$ at rest and $5.1 \%(2.9 \%)$ during exercise. The mean work load was 102 (range 75-120) watts. No subject showed arterial oxygen desaturation with exercise.

Of the 12 patients studied during exercise, eight (all patients in table 3 and patients 21 and 26 in table 4) increased their shunts from a mean of $33.7 \%(12.7 \%)$ at rest to $41.7 \%$ $(13.3 \%)$ during exercise; the remaining four patients decreased their shunt from a mean of
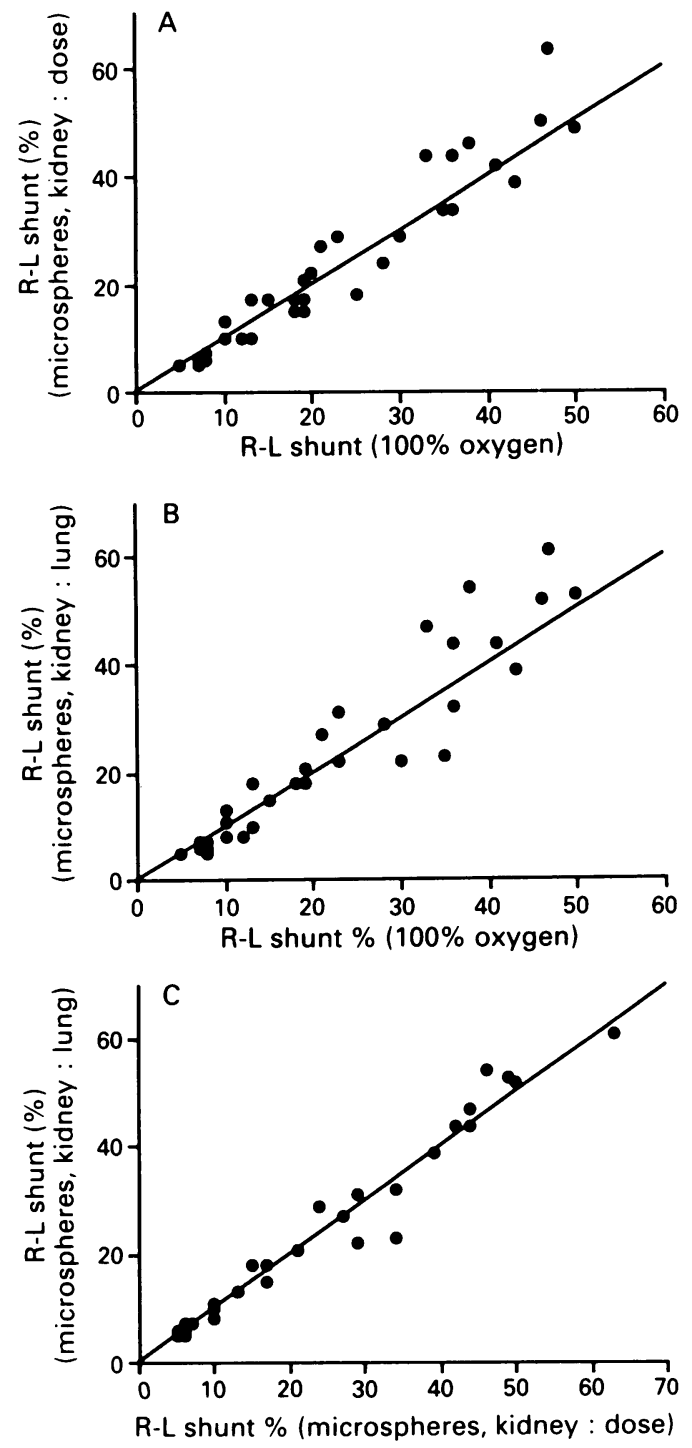

Figure 2 A-Anatomical right to left shunt as measured by ${ }^{99 m}$ Tc microspheres (kidney:dose) plotted against shunt measured by the $100 \%$ oxygen breathing method.

$(n=36)$ (line of identity shown). B-Anatomical right to left shunt as measured by ${ }^{99 m} T c$ microspheres

(kidney:lung) plotted against shunt measured by the $100 \%$ oxygen breathing method $(n=32)$ (line of identity shown). C-Anatomical right to left shunt as measured by ${ }^{99 m}$ Tc microspheres; kidney:dose method plotted against kidney:lung method $(n=32$ ) (line of identity shown).

$22 \cdot 6 \%(2 \cdot 2 \%)$ at rest to $17 \cdot 6 \%(2 \cdot 4 \%)$ during exercise. Change in oxygen saturation with exercise correlated with $f$ values $(r=\quad+0 \cdot 80$; fig 4).

The 12 patients were classified according to whether the residual right to left shunt after embolisation of most or all of the arteriovenous malformations with a feeding vessel greater than $3 \mathrm{~mm}$ in diameter was $10 \%$ and over or below $10 \%$ (a large residual shunt suggests the continuing presence of diffuse, small arteriovenous malformations). Patients with a residual shunt greater than $10 \%$ (table 3 ) increased their right to left shunt on exercise from a mean (SD) of $37.5 \%(10.5 \%)$ at rest to $46.5 \%(10.4 \%)$ during exercise $(\mathrm{p}<0.001$, $\mathrm{n}=11$ ). Patients with a residual shunt of less than $10 \%$ (table 4 ) showed a slight fall in right to left shunt from $22 \cdot 1 \%(7 \cdot 2 \%)$ at rest to $20 \cdot 7 \%(10 \cdot 1 \%)$ during exercise $(\mathrm{p}=0 \cdot 54, \mathrm{n}=$ 

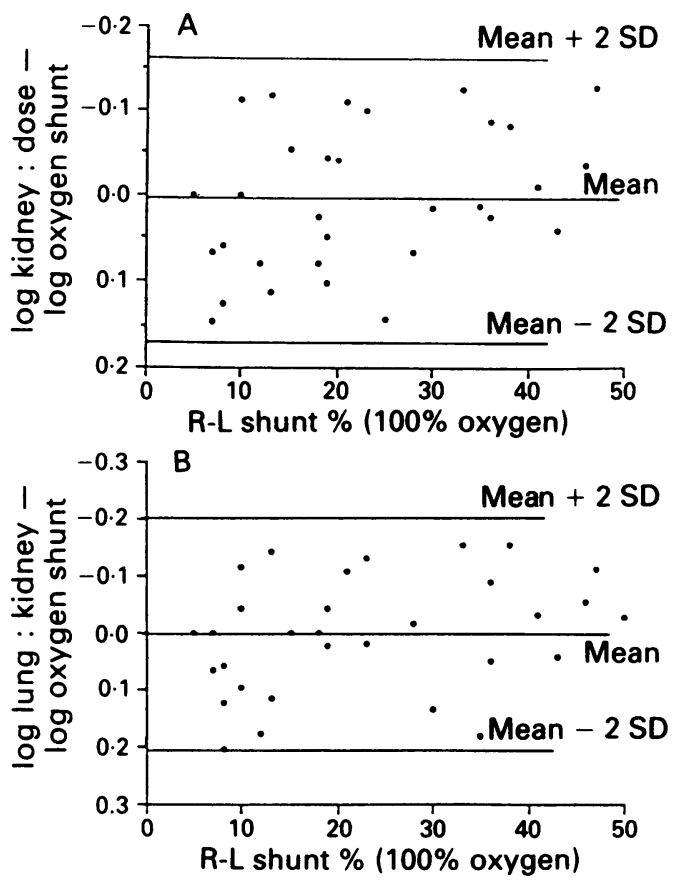

Figure $3 A-B$ land-Altman plot of difference (log) between ${ }^{99 m}$ Tc microsphere shunt (kidney:dose) and $100 \%$ oxygen shunt against the reference technique (100\% oxygen breathing). B-Bland-Altman plot of difference (log) between ${ }^{99 m}$ Tc microsphere shunt (kidney:lung) and 100\% oxygen shunt against the reference technique.

Table 2 fvalue / lung counts(exercise)/lung counts (rest) / and right to left shunt ( ${ }^{99 m} T c$ microspheres) at rest and during exercise in five normal subjects

\begin{tabular}{llll}
\hline \multirow{2}{*}{$\begin{array}{l}\text { Normal } \\
\text { subjects }\end{array}$} & & \multicolumn{2}{c}{ Right to left shunt $(\%)$} \\
\cline { 2 - 4 } & fvalue & Rest & Exercise \\
\hline 1 & 0.94 & 1.3 & 7.2 \\
2 & 0.94 & 1.8 & 7.7 \\
3 & 1.03 & 3.0 & 0.6 \\
4 & 0.98 & 4.1 & 6.9 \\
5 & 1.00 & 4.3 & 4.3 \\
Mean & & & \\
SD & 0.98 & 2.9 & 5.1 \\
SE & 0.04 & 1.3 & 2.9 \\
\hline
\end{tabular}

7). There were significant differences between the two groups for the $f$ value $(p=0.025)$ and exercise desaturation $(p=0.009)$.

\section{Discussion}

MICROSPHERE MEASUREMENT OF SHUNT

Measurement of right to left shunt with radiolabelled particles was first described in $1969^{15}$ and quantification was attempted by Gates in $1974 .^{16}$ The microsphere method described here improves quantification by measuring systemic activity from the right kidney only (to avoid problems with splenic activity overlying the left kidney) and also by allowing for tissue attenuation. More important, agreement between the ${ }^{99 \mathrm{~m}} \mathrm{Tc}$ microsphere shunt and the $100 \%$ oxygen breathing shunt is good (figs 2A-C), even though the former measures an anatomical shunt and the latter a functional (physiological) shunt. The microsphere method is less invasive (arterial blood gas sampling is not required), quicker, and less uncomfortable for the subject than the oxygen method. The radiation dose received is relatively small $(0.5 \mathrm{mS})$.

\section{MICROSPHERE SHUNT MEASUREMENTS AT REST}

The mean (SD) shunt in normal subjects was $2 \cdot 7 \%(1 \cdot 2 \%)$ with the kidney:lung microsphere method. $100 \%$ oxygen shunt measurements were not performed on our normal volunteers. Measurements of the very small right to left shunt in normal subjects are unlikely to be as accurate with the classical $100 \%$ oxygen breathing method $^{9}$ because they require measurement of high partial pressures of oxygen. Moreover, the retention of small quantities of alveolar nitrogen trapped behind closed bronchioles may raise the right to left shunt by $1-5 \%$, especially in elderly subjects and even when deep breathing is used. ${ }^{17}$ The anatomic right to left shunt (from Thebesian and bronchial veins draining to the left ventricle) appears to be independent of age, according to measurements obtained during exercise when subjects were breathing $100 \%$ oxygen. ${ }^{18}$ The values for right to left shunt obtained by

Table 3 Workload, right to left shunt, arterial oxygen saturation ( $\mathrm{SaO}_{2}$ ), kidney:dose radioactive count ratio at rest and during exercise (Ex) and residual shunt after embolisation of all macroscopic pulmonary arteriovenous malformations in patients with residual shunts of $10 \%$ or more

\begin{tabular}{|c|c|c|c|c|c|c|c|c|c|c|}
\hline \multirow{2}{*}{$\begin{array}{l}\text { Patient } \\
\text { No }\end{array}$} & \multirow[b]{2}{*}{ Study } & \multirow[b]{2}{*}{ Work (w) } & \multirow[b]{2}{*}{ fvalue } & \multicolumn{2}{|c|}{ Shunt (\%) } & \multicolumn{2}{|l|}{$\mathrm{SaO}_{2}(\%)$} & \multicolumn{2}{|c|}{ Kidney: dose } & \multirow{2}{*}{$\begin{array}{l}\text { Residual } \\
\text { shunt (\%) }\end{array}$} \\
\hline & & & & Rest & $E x$ & $R e s t-E x$ & $\Delta \dagger$ & Rest & $E x$ & \\
\hline \multirow[t]{3}{*}{1} & 1 & 45 & 0.84 & 44 & 53 & $78-70$ & -8 & 44 & 41 & \\
\hline & 2 & 45 & 0.73 & 42 & 57 & $78-69$ & -9 & 42 & 41 & \\
\hline & 3 & 45 & 0.89 & 43 & 41 & $80-75$ & -5 & 33 & 23 & 29 \\
\hline \multirow[t]{2}{*}{2} & 1 & 30 & 0.92 & 47 & 51 & $64-59$ & -5 & 47 & 45 & \\
\hline & 2 & 30 & 0.88 & 48 & 54 & $77-72$ & -5 & 48 & 29 & 48 \\
\hline \multirow[t]{2}{*}{3} & 1 & 75 & 0.74 & 35 & 52 & $78-70$ & -8 & 35 & 19 & \\
\hline & 2 & 75 & 0.95 & 24 & 28 & $78-75$ & -3 & 24 & 13 & 25 \\
\hline 5 & 1 & 75 & 0.87 & 17 & 28 & $87-83$ & -4 & 17 & 11 & 15 \\
\hline $20^{\star}$ & 1 & 30 & 0.91 & 18 & 25 & $77-71$ & -6 & 18 & 7 & NA \\
\hline \multirow[t]{3}{*}{24} & 1 & 45 & $1 \cdot 21$ & 50 & 39 & $72-69$ & -3 & 50 & 25 & \\
\hline & 2 & 45 & 0.78 & 41 & 54 & $72-61$ & -11 & 41 & 34 & \\
\hline & 3 & 45 & 0.80 & 31 & 45 & $86-81$ & -5 & 31 & 12 & 31 \\
\hline Mean & & $50 \cdot 5$ & 0.87 & $37 \cdot 5$ & $46 \cdot 5$ & & $-6 \cdot 2$ & $37 \cdot 5$ & $26 \cdot 6$ & $29 \cdot 6$ \\
\hline SD & & $16 \cdot 8$ & 0.13 & $10 \cdot 5$ & 10.4 & & 2.5 & 10.5 & $12 \cdot 4$ & $12 \cdot 0$ \\
\hline SE & & $5 \cdot 1$ & 0.04 & $3 \cdot 2$ & $3 \cdot 1$ & & 0.8 & $3 \cdot 2$ & $3 \cdot 7$ & $5 \cdot 4$ \\
\hline
\end{tabular}

*Data from patient 20 were excluded from statistical analysis as residual shunt was not available (NA).

$+\Delta$ represents the difference between $\mathrm{SaO}_{2}$ at rest and during exercise. 
Figure 4 Arterial oxygen desaturation $\left(\mathrm{SaO}_{2}\right.$ (rest)

- $\mathrm{SaO}_{2}$ (exercise)) during exercise plotted against the f value / lung counts (exercise) - lung counts $($ rest $) /. f<1.0$ implies an increase in right to left shunt and $>>1.0 a$ decrease in shunt with exercise.

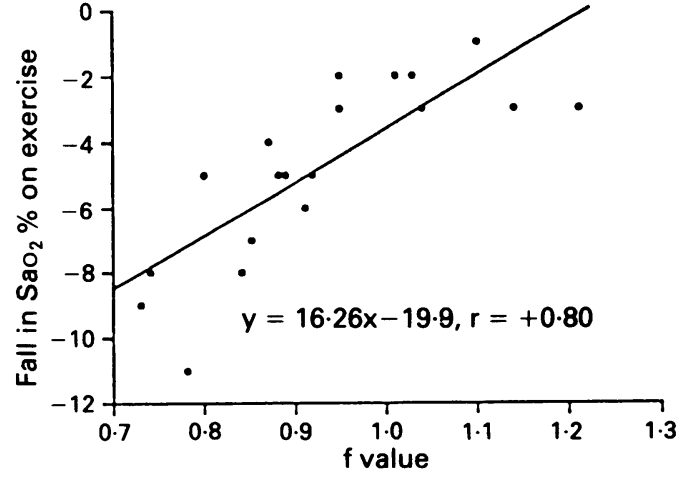

Harris et al. ${ }^{18}$ represented $1.55-1.88 \quad(0.5-$ $1 \cdot 1) \%$ of cardiac output, so $4.08 \%$ (mean +2 SD) may be regarded as the upper limit of normal for the right to left shunt during exercise. This agrees well with the right to left shunt in young normal subjects at rest $^{17}$ of $0.6 \%(1.74 \%)$ and our own values of $2.7 \%$ $(1 \cdot 2 \%)$ obtained with radiolabelled microspheres at rest.

There was a close correlation between the microsphere and reference methods for measurement of right to left shunt (fig 2). Limits of agreement obtained for the kidney:dose method show that if a microsphere shunt of $10 \%$ is obtained there is $95 \%$ confidence that the shunt measured by the $100 \%$ oxygen method would lie in the range $7-14 \%$. For a $20 \%$ shunt the limits would be $14-28 \%$. Theoretically the reliability would be greater for sequential studies in the same subject as any variation due to the attenuation coefficient should be minimal.

\section{MICROSPHERE SHUNT MEASUREMENTS DURING EXERCISE}

The mean right to left shunt in the five normal subjects was $2.9 \%(1.3 \%)$ at rest, rising to $5 \cdot 1 \%(2.9 \%)$ with exercise. The microsphere shunt rises with exercise, probably because vasodilation of the pulmonary capillary bed allows an increased fraction of microspheres to pass through the capillaries although these vessels allow normal gas exchange. The normal subjects did not desaturate with exercise, which is further evidence that effective gas exchange was occurring.

In the 12 patients with pulmonary arteriovenous malformations in whom right to left shunt was measured at rest and during exercise an inverse correlation was found between the degree of arterial desaturation with exercise and the $f$ value-that is, those who had greater desaturation had smaller $f$ values, reflecting increased right to left shunt with exercise. Measurements of right to left shunt while subjects were breathing $100 \%$ oxygen would have required arterial cannulation and were not made during exercise. The good correlation between the extent of arterial oxygen desaturation during exercise and the change in right to left shunt from rest to exercise (fig 4) is encouraging, however. Interestingly, the kidney:dose ratio invariably declined with exercise, irrespective of whether the relative shunt was increasing or decreasing (tables 3 and 4). This reflects the smaller proportion of the cardiac output that is distributed to the kidneys during exercise than during rest.

Patients who were left with a residual shunt of $10 \%$ or more after embolisation of all pulmonary arteriovenous malformations with macroscopic feeding vessels (table 3 ) increased their right to left shunt with exercise from mean (SD) $37.5 \%(10.5 \%)$ at rest to $46.5 \%$ $(10.4 \%)(\mathrm{p}<0.001, \mathrm{n}=11)$. In contrast, patients who were later shown not to have diffuse pulmonary arteriovenous malformations, with no residual shunt (table 4), showed a slight fall in right to left shunt with exercise, from $22 \cdot 1 \%(7 \cdot 2 \%)$ at rest to $20 \cdot 7 \%(10 \cdot 1 \%)$. These results imply differences in the way different sizes of arteriovenous malformation behave during exercise. The feeding vessels associated with small, diffuse arteriovenous malformations may be more compliant than their neighbouring normal vessels and distend relatively more when pulmonary arterial pressure rises with exercise, causing a relative and absolute increase in right to left shunt flow with exercise. In contrast, larger feeding vessels associated with the bigger arteriovenous malformations may have a limited capacity to dilate, so that absolute shunt flow is unchanged during exercise or may decrease as a proportion of the increased cardiac output with exercise.

Why do the patients with larger arteriovenous malformations show further arterial desaturation during exercise of $2.9 \%$ (SD $2.0 \%$ ) when they have not increased their right to left shunt? We postulate that this is due to

Table 4 Workload, right to left shunt, arterial oxygen saturation ( $\mathrm{SaO}_{2}$ ), kidney:dose radioactive count ratio at rest and during exercise (Ex), and residual shunt after embolisation of all macroscopic pulmonary arteriovenous malformations in patients with residual shunts of less than $10 \%$

\begin{tabular}{|c|c|c|c|c|c|c|c|c|c|c|}
\hline \multirow{2}{*}{$\begin{array}{l}\text { Patient } \\
\text { No }\end{array}$} & \multirow[b]{2}{*}{ Study } & \multirow[b]{2}{*}{ Work (w) } & \multirow[b]{2}{*}{ fvalue } & \multicolumn{2}{|c|}{ Shunt (\%) } & \multicolumn{2}{|l|}{$\mathrm{SaO}_{2}(\%)$} & \multicolumn{2}{|c|}{ Kidney: dose } & \multirow{2}{*}{$\begin{array}{l}\text { Residual } \\
\text { shunt (\%) }\end{array}$} \\
\hline & & & & Rest & $E x$ & $R e s t-E x$ & $\Delta$ & Rest & $E x$ & \\
\hline 4 & 1 & 75 & $1 \cdot 14$ & 26 & 16 & $95-92$ & -3 & 26 & 13 & 4 \\
\hline 21 & 1 & 45 & $0 \cdot 85$ & 33 & 43 & $81-74$ & -7 & 33 & 20 & 5 \\
\hline \multirow[t]{2}{*}{22} & 1 & 30 & $1 \cdot 04$ & 22 & 19 & $83-80$ & -3 & 22 & 13 & \\
\hline & 2 & 30 & $1 \cdot 10$ & 23 & 15 & $89-88$ & -1 & 23 & 12 & 9 \\
\hline 23 & 1 & 60 & 1.03 & 20 & 17 & $88-86$ & -2 & 20 & 10 & 5 \\
\hline 25 & 1 & 60 & 1.01 & 22 & 21 & 93-91 & -2 & 22 & 5 & 2 \\
\hline 26 & 1 & 45 & 0.95 & 9 & 14 & $93-91$ & -2 & 9 & 2 & 2 \\
\hline Mean & & $49 \cdot 3$ & 1.02 & $22 \cdot 1$ & $20 \cdot 7$ & & -2.9 & $24 \cdot 3$ & $12 \cdot 2$ & $4 \cdot 5$ \\
\hline SD & & $16 \cdot 7$ & $0 \cdot 10$ & $7 \cdot 2$ & $10 \cdot 1$ & & $2 \cdot 0$ & $4 \cdot 7$ & 4.9 & $2 \cdot 6$ \\
\hline SE & & $6 \cdot 3$ & 0.04 & $2 \cdot 7$ & $3 \cdot 8$ & & 0.7 & 1.9 & $2 \cdot 0$ & $1 \cdot 1$ \\
\hline
\end{tabular}

$\Delta$ represents the difference between $\mathrm{SaO}_{2}$ at rest and during exercise. 
recirculation of increasingly hypoxic mixed venous blood through the arteriovenous malformations. Patients with residual shunts of $10 \%$ or more after embolisation, who are presumed to have diffuse arteriovenous malformations, showed arterial desaturation of $6.2 \%$ $(2.5 \%)$ with exercise (table 3$)$. These results, combined with those in table 4 , suggest that half of their arterial desaturation is due to an increase in their right to left shunt percentage and half is due to the increased desaturation of mixed venous blood.

This paper focuses on measurements of intrapulmonary right to left shunt in patients with pulmonary arteriovenous malformations and the mechanisms of arterial desaturation during exercise. For clinical practice we have shown that measurements of right to left shunt with radiolabelled microspheres are a convenient, accurate, and specific way of quantifying the physiological effect of pulmonary arteriovenous malformations and monitoring the effects of treatment by coil embolisation.

1 Hughes JMB, Allison DJ. Pulmonary arteriovenous malformations: the radiologist replaces the surgeon. Clin Radiol 1990;41:297-8

2 Terry PB, Barth KH, Kaufman SL, White RI Jr. Balloon embolization for treatment of pulmonary arteriovenous fistulas. $N$ Engl J Med 1980;302:1189-90.

3 White RI Jr, Lynch-Nyhan A, Terry P, Buescher PC Farmlett EJ, Charnas L, et al. Pulmonary arteriovenous malformations: techniques and long term outcome of embolotherapy. Radiology 1988;169:663-9.

4 Dines DE, Seward JB, Bernatz PE. Pulmonary arteriovenous fistulas. Mayo Clin Proc 1983;58:176-81.
5 Burke CM, Safai C, Nelson DP, Raffin TA. Pulmonary arteriovenous malformations: a critical update. $A m R e v$ Respir Dis 1986;134:334-9.

6 Hartnell GG, Allison DJ. Management of pulmonary arteriovenous malformations. $\mathrm{Br} J$ Hosp Med 1988;39: 197-202.

7 Dines DE, Arms RA, Bernatz PE, Gomes MR. Pulmonary arteriovenous fistulas. Mayo Clin Proc 1974;49:460-5.

8 Chilvers ER, Whyte MKB, Jackson JE, Allison DJ, Hughes JMB. Effect of percutaneous transcatheter embolization on JMB. Effect of percutaneous transcatheter embolization on
pulmonary function, right to left shunt and arterial oxygenation in patients with pulmonary arteriovenou malformations. Am Rev Respir Dis 1990;142:420-5.

9 Berggren SM. The oxygen deficit of arterial blood caused by non-ventilating parts of the lung. Acta Physiol Scand 1942;4(suppl II):1-92.

10 Chilvers ER, Peters AM, George P, Hughes JMB, Allison DJ. Quantification of right to left shunt through pulmonary arteriovenous malformations using 99-Tc albumin microspheres. Clin Radiol 1988;39:611-4.

11 Huseby JS, Culver BH, Butler J. Pulmonary arteriovenous fistulas: increase in shunt at high lung volume. Am Rev Respir Dis 1977;115:229-32.

12 Peters AM, Brown J, Hartnell GG, Myers MJ, Haskell C Lavender JP. Non-invasive measurement of renal blood flow with Tc-99m DTPA: comparison with radiolabelled microspheres. Cardiovasc Res 1987;21:830-4.

13 Peters AM, Gunasekera RD, Henderson BL, Brown J Lavender JP, De Souza $\mathrm{M}$, et al. Non-invasive measurement of blood flow and extraction fraction. Nucl Med Commun 1987;9:823-37.

14 Bland JM, Altman DG. Statistical methods for assessing agreement between two methods of clinical measurement. Lancet 1986; $\mathrm{i}: 307-10$.

15 Haroutunian LM, Neill CA, Wagner HN. Radioisotope scanning of the lung in cyanotic congenital heart disease. Am J Cardiol 1969;23:387-95.

16 Gates GF, Orme HW, Dore EK. Cardiac shunt assessment in children with macroaggregated albumin technetium$99 \mathrm{~m}$. Radiology 1974;112:649-53.

17 Rea HH, Withy SJ, Seelye ER, Harris EA. The effect of posture on venous admixture and respiratory dead space in health. Am Rev Respir Dis 1977;115:571-80

18 Harris EA, Seelye ER, Whitlock RML. Gas exchange during exercise in healthy people. Clin Sci Mol Med 1976; 51:335-44. 